\title{
Ventral Schwannoma of the Thoracolumbar Spine
}

\author{
Hitoshi Yamahata ${ }^{1}$, Satoshi Yamaguchi ${ }^{2}$, Masanao Mori ${ }^{1}$, \\ Fumikatsu Kubo ${ }^{1}$, Hiroshi Tokimura ${ }^{1}$, Kazunori Arita ${ }^{1}$ \\ ${ }^{1}$ Department of Neurosurgery, Graduate School of Medical and Dental Sciences, Kagoshima University, Kagoshima, Japan \\ ${ }^{2}$ Department of Neurosurgery, Hiroshima University Graduate School of Biomedical Sciences, Hiroshima, Japan
}

We report two patients with ventral schwannoma in the thoracolumbar region manifesting as low back pain with or without paraparesis. In both patients magnetic resonance imaging (MRI) revealed a heterogeneously-enhanced intradural extramedullary mass in the thoracolumbar region. The tumors were successfully removed via the posterior approach. Their histology was consistent with schwannoma. Postoperative MRI showed no evidence of a tumor in either patient. Spinal schwannomas are common benign intradural extramedullary spinal neoplasms; most arise from the dorsal- and very few from the anterior roots. A literature review revealed that ventral schwannomas, including giant tumors as in the one from case 2 in our study, affect mainly the cervical region, and most are surgically addressed via the posterior approach. Careful handling of the spinal cord is mandatory for satisfactory surgical results.

Keywords: Spinal schwannoma; Intradural lesion; Ventral schwannoma; Giant

\section{Introduction}

Spinal schwannomas are common benign intradural extramedullary spinal neoplasms; they comprise approximately $30 \%$ of all spinal tumors [1]. Most spinal schwannomas arise from the dorsal root [2] and of the less than $5 \%$ originating at the anterior roots [3], very few involve the thoracolumbar region $[4,5]$. Compared to dorsal schwannomas, the treatment of ventral tumors is technically challenging [5]. Since their ventral location inhibits tumor visualization, the surgical removal of these lesions may result in iatrogenic spinal cord injury. Consequently, different surgical approaches have been suggested [5-9]. We report two patients with ventral intradural extramedullary schwannomas at the thoracolumbar spine that we addressed via the posterior approach.

\section{Case Report}

A 43-year-old woman suffered lumbago and bilateral leg pain for one month. Neurological examination revealed paresthesia of the dorsal aspects of both legs. Magnetic resonance imaging (MRI) showed a ventrally located intradural extramedullary mass at the level of T12 (Fig. 1A, B). Three-dimensional computed tomography angiography (3D-CTA) revealed that the Adamkiewicz artery (AKA) ran from the L2 foramen to the spinal cord (Fig. $1 C, D)$. The patient was placed in the prone position and treated via the posterior approach. We performed T11 to L3 hemilaminectomy on the left side to expose the dorsal aspect of the spinal cord. After opening the dura mater it was seen that part of the tumor was located at the left ventral side of the spinal cord. We detached the dentate

Received May 9, 2012; Revised Aug 30, 2012; Accepted Sep 13, 2012

Corresponding author: Hitoshi Yamahata

Department of Neurosurgery, Graduate School of Medical and Dental Sciences, Kagoshima University,

8-35-1 Sakuragaoka, Kagoshima, Kagoshima 890-8520, Japan

Tel: +81-99-275-5375, Fax:+81-99-265-4041, E-mail: yamahatad3@gmail.com 
ligament on the left side from the dura mater and gently reflected it to make space ventral to the spinal cord. The tumor capsule, partially exposed by this maneuver, was cauterized and we proceeded to perform internal decompression of the tumor from this corridor using an ultrasonic aspirator. Intraoperatively, motor evoked potentials
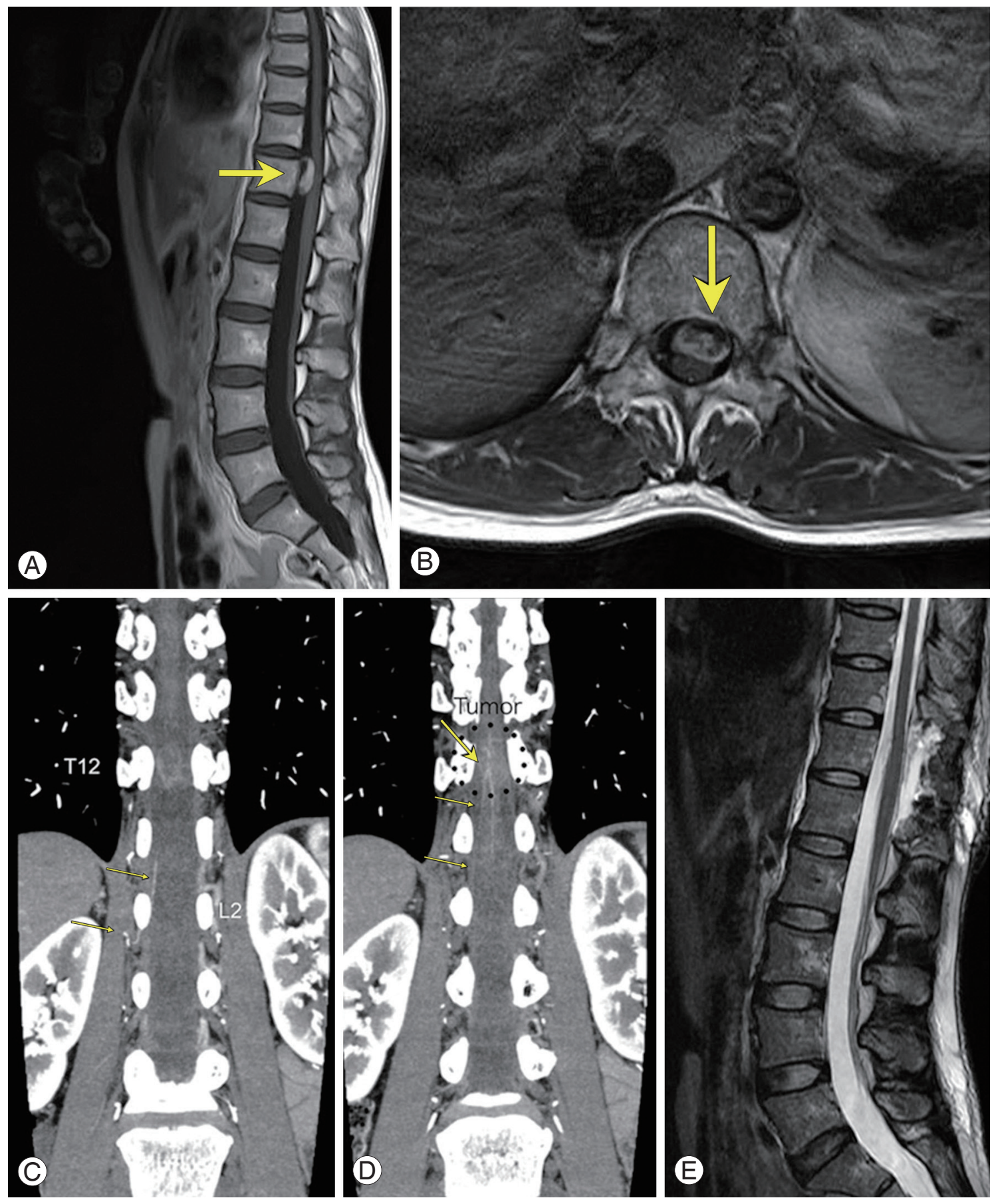

Fig. 1. (A) T1-weighted contrast-enhanced sagittal- and (B) axial magnetic resonance imaging (MRI) showing an intradural extramedullary mass at the level of T12 (arrow). (C) The mass is heterogeneously Gd-enhanced. 2D multiplanar reconstruction images (coronal view) prepared from computed tomography angiograms show an Adamkiewicz artery (AKA) running from the foramen of L2 to the spinal cord (small arrows). (D) The AKA manifests the characteristic hairpin turn connection with the anterior spinal artery (large arrow). The dotted circle indicates the location of the tumor. (E) Postoperative T2-weighted MRI revealed total resection of the tumor. 
elicited by the stimulation of nerve roots attached to the tumor capsule identified the upper lumbar nerves as the tumor origin. Sharp dissection of the tumor capsule away from the pia mater of the spinal cord was carried out with ease and total removal of the tumor was achieved with resection of the associated rootlets. Postoperatively, her symptoms improved and she was discharged 10 days after the operation. The pathological diagnosis was schwannoma. Postoperative MRI showed no evidence of a residual tumor (Fig. 1E).

\section{Case 2}

A 77-year-old man suffered progressively worsening low back pain for 5 months and mild weakness in both legs for 4 months. Neurological examination revealed paraparesis in both lower extremities (manual muscle testing [MMT] 2 in left- and 3 in the right leg). MRI demonstrated an intradural-extramedullary tumor extending from T10 to T12 on the ventral side to the spinal cord (Fig. $2 \mathrm{~A}-\mathrm{C})$. The tumor was isointense with the spinal cord on T1- and hyperintense on T2-weighted images (Fig. 2A). It was also well enhanced (Fig. 2B). On axial enhanced images at the level of T11-T12 the tumor extended later- ally into the intervertebral foramina on the right side (Fig. $2 \mathrm{C})$. With the patient in the prone position and under general anesthesia we attempted total tumor removal. After the midline skin incision we performed T9 to T12 laminectomy and opened the dura mater. The tumor was not seen from the dorsal side because of its ventral location. After cutting the dentate ligament of the right side and carefully mobilizing the spinal cord by reflecting the ligament we could see a tumor with a yellowish gray hue. After internal decompression using an ultrasonic aspirator we proceeded to dissect the tumor from the spinal cord. During the dissecition of the tumor, we were able to identify one large nerve root that entered and descended into the tumor. As it was difficult to shave it into constituent rootlet bundles we cut the nerve root at the level of T12 and completely removed the tumor capsule. Based on operative findings we concluded that the exact tumor origin was T12 or L1. His somatosensory- and motor evoked potentials remained stable throughout the operation.

Postoperatively this patient suffered transient worsening of paraparesis predominantly on the right side. Over the course of his hospitalization, his motor weakness of the left lower extremity improved to MMT3, however, his
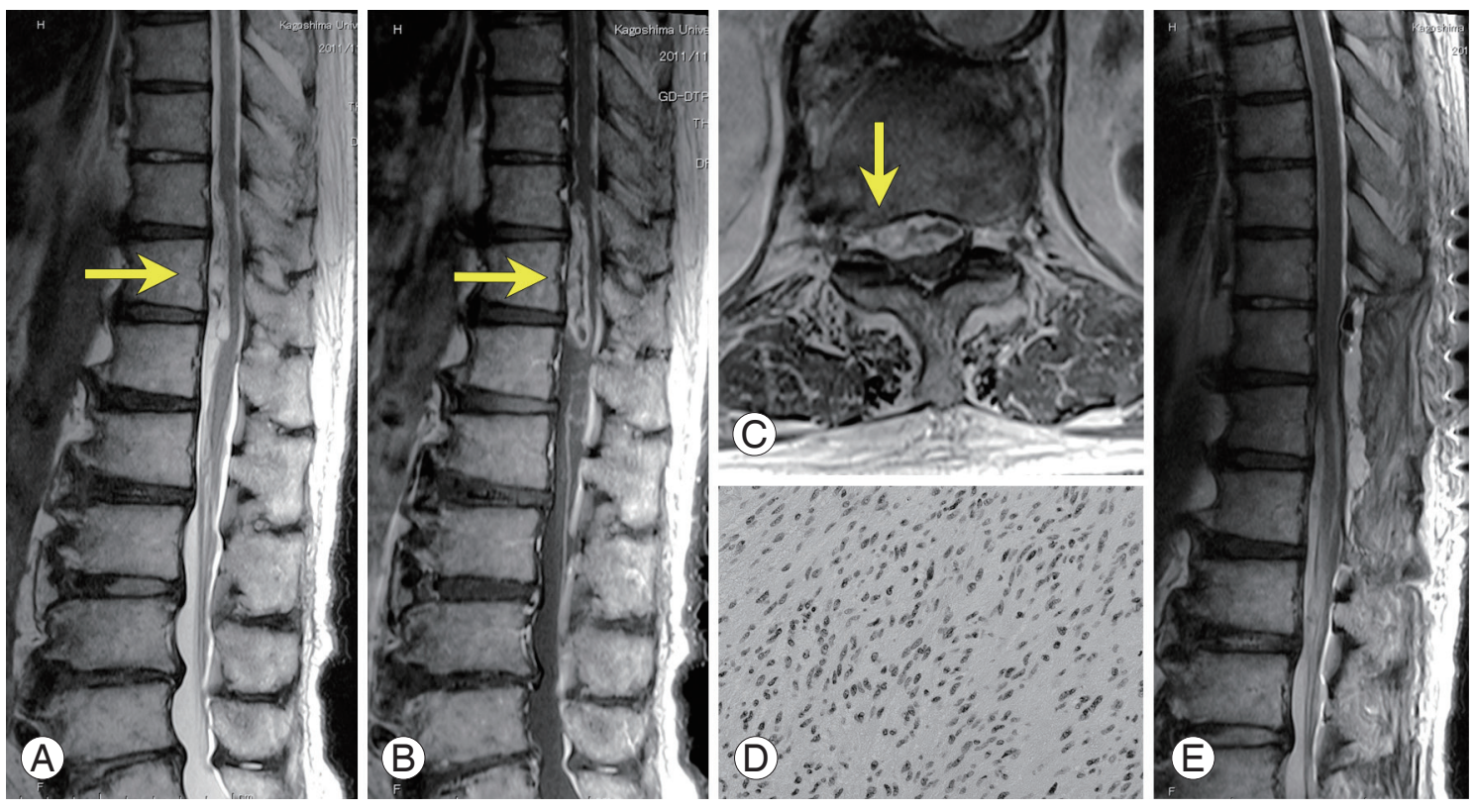

Fig. 2. (A) T2-weighted sagittal- and (B) T1-weighted contrast-enhanced sagittal magnetic resonance imaging (MRI) showing an intradural extramedullary mass (arrow). It is hyperintense on T2-weighted images and heterogeneously Gd-enhanced. (C) Axial enhanced images of the T11-12 level show that the heterogeneous mass extended laterally into the intervertebral foramina on the right side (arrow). (D) Photographs of the surgical specimen show a typical schwannoma (H\&E stain, $\times 200)$. (E) Postoperative T2weighted MRI confirmed total resection of the tumor. 
Table 1. Review of intradural, extamedullary schwannomas at the ventral portion

\begin{tabular}{|c|c|c|c|c|c|c|}
\hline $\begin{array}{l}\text { Case } \\
\text { No. }\end{array}$ & Author, year & $\begin{array}{l}\text { Age }(y r) / \\
\text { Sex }\end{array}$ & $\begin{array}{c}\text { Vertebral level on } \\
\text { examination }\end{array}$ & Origin & Treatment & Outcome \\
\hline 1 & Crockard and Sen [10], 1991 & $46 / \mathrm{M}$ & Clivus to $\mathrm{C} 1$ & C1 & Transoral approach & Soft palate deformity \\
\hline 2 & & $32 / \mathrm{M}$ & FM to C2 & C1 & Transoral approach & Good \\
\hline 3 & Steck et al. [11], 1994 & $N A / F$ & Thoracic & NA & Posterolateral approach & NA \\
\hline 4 & Ashour et al. [8], 1999 & $32 / F$ & FM to T10 & C7 & Posterior laminectomy & Good \\
\hline 5 & Singer et al. [12], 1999 & $27 / \mathrm{M}$ & C7 to T2 & Unknown & Posterior laminectomy & Good \\
\hline 6 & Kanemoto et al. [3], 1999 & $39 / \mathrm{M}$ & $\mathrm{T} 1$ & $\mathrm{~T} 1$ & $\begin{array}{l}\text { Hemilaminectomy with } \\
\text { partial facetectomy }\end{array}$ & Good \\
\hline 7 & 0’Toole and McCormick [6], 2003 & $54 / \mathrm{M}$ & C3 to C6 & Unknown & $\begin{array}{l}\text { Anterior approach with } \\
\text { corpectomies }\end{array}$ & Good \\
\hline 8 & Parlato et al. [13], 2003 & $\mathrm{NA} / \mathrm{NA}$ & C1 & C1 & Transcondylar approach & NA \\
\hline 9 & Ueda et al. [1], 2006 & $79 / F$ & $\mathrm{FM}$ to $\mathrm{C} 1$ & C1 & Transcondylar approach & Good \\
\hline 10 & & $50 / F$ & $\mathrm{FM}$ to $\mathrm{C} 1$ & C1 & Transcondylar approach & CSF leak \\
\hline 11 & & $54 / F$ & FM to $\mathrm{C} 1$ & C1 & Transcondylar approach & Good \\
\hline 12 & Casha et al. [14], 2008 & $31 / \mathrm{M}$ & C2 to C4 & C4 & Anterior approach & Good \\
\hline 13 & Mahore et al. [15], 2009 & $33 / F$ & C2 to T3 & Unknown & Posterolateral approach & Good \\
\hline 14 & Yasuda et al. [7], 2009 & $71 / \mathrm{M}$ & C2 to T3 & C3 & Anterolateral approach & Good \\
\hline 15 & Mahore et al. [2], 2010 & 18/M & Clivus to $\mathrm{C} 7$ & Unknown & Posterior laminectomy & Good \\
\hline 16 & Chen et al. [9], 2010 & $45 / \mathrm{M}$ & $\mathrm{T} 11$ & NA & Posterior approach & Motor weakness \\
\hline 17 & Angevine et al. [5], 2011 & $\mathrm{NA} / \mathrm{NA}$ & $\mathrm{C} 2$ to $\mathrm{C} 3$ & C3 & $\begin{array}{l}\text { Anterior approach with } \\
\text { corpectomies }\end{array}$ & Swallowing difficulties \\
\hline 18 & & $\mathrm{NA} / \mathrm{NA}$ & T8 to T9 & NA & Posterior approach & Hemisensory deficit \\
\hline 19 & Present case & $43 / F$ & $\mathrm{~T} 12$ & Lumbar & Posterior laminectomy & Good \\
\hline 20 & Present case & $77 / \mathrm{M}$ & T10 to T12 & T12 or L1 & Posterior laminectomy & Motor weakness \\
\hline
\end{tabular}

FM, foramen magnum; NA, not available; CSF, cerebrospinal fluid.

right leg remained at muscle power grade 2. The histological diagnosis was typical schwannoma (Fig. 2D). He was transferred to a rehabilitation facility 2 weeks after the operation and subsequently returned to his home. At the 6-month follow-up examination, he could walk without assistance. Postoperative MRI confirmed total tumor removal (Fig. 2E).

\section{Discussion}

As most schwannomas typically arise from the dorsal root, their location tends to be lateral and posterior to the spinal column. Schwannomas originating from the anterior roots account for less than $5 \%$ of all spinal schwannomas [3]. Our search of the literature found 18 previouslyreported ventral schwannomas (Table 1) [1-3,5-15]; this number does not include ventral tumors with a dumbbell shape, tumors that occupied the intradural as well as extradural space, or reports devoid of radiological findings. The 20 patients (including ours) comprised 10 males and 7 females, and in 3 the gender was not disclosed. They ranged in age from 18 to 79 years (mean, 45.6 years). 
Preoperative imaging studies showed that vertebral levels from the clivus to T12 were involved. The origin of the tumors included the cervical ventral roots $(n=10)$, the thoracic ventral root $(n=1)$, the lumbar ventral root (our case 1), and the thoracolumbar ventral root (our case 2). Including case 2 from our study there were 7 patients with giant spinal schwannomas, defined as those that extend over more than two vertebral levels $[2,6]$.

Some ventral schwannomas have no attachment to nerve roots and their origin is recorded as unknown in the table $[2,6]$. In such cases, multiple hypotheses have been offered to explain the aberrant location of Schwanncell-based tumors. For example, it has been suggested that their origin is the perivascular nerve plexus surrounding vessels arising from the anterior spinal artery $[2,6]$. Another hypothesis suggests the migration of residual neural crest progenitors into the central nervous system parenchyma during embryogenesis [2]. Our operative findings indicated that the tumor originated from the anterior root of the upper lumbar nerve in case 1 and at the level of T12 or L1 in case 2. The monitoring of motor evoked potentials was useful for the detection of the tumor origin when the affected nerve controlled motor functions.

The surgical access route to extramedullary tumors should be based on the location of the tumor, its spread, and the region to which it is localized. Although most intradural lesions in the vertebral column can be accessed by a posterior or posterolateral approach [6], masses located ventral to the spinal cord pose a difficult surgical challenge $[3,5]$. The anterior approach was employed in 6 instances and the posterior approach in 14 instances (Table 1). If the tumor is located in the upper cervical spine or on the craniocervical level, a dorsolateral craniospinal- or far lateral access route may be most convenient [5]. The anterior approach is appropriate to address ventral midline intradural tumors that are small, next to the ventral surface of the spinal cord and that produce no significant displacement or rotation of the spinal cord $[4,6]$. If the tumor is a giant schwannoma and involves long segments, the posterior is more advantageous than the anterior approach. As shown in the table, 5 of 7 giant ventral schwannomas were approached using the posterior route.

The consistency of the tumor should be taken into consideration when choosing the operative approach. Soft tumors are easily handled with the posterior or posterolateral approach and the treatment outcomes were satisfactory [2], however, the management of ventrallylocated tumors that are hard and involve long segments is more difficult. Endoscopy-assisted removal, recently introduced to treat ventral intradural spinal tumors [2], allows inspection of the interface between the tumor and the ventral surface of the spinal cord with minimal cord retraction.

In their precise description regarding the anatomy of spinal roots, Arslan et al. [16] reported that from the distal to the proximal side, spinal roots are broken up into a series of rootlets attached to the spinal cord. Considering this anatomical feature, it may be possible to remove small- and proximally-located tumors with sparing of the normal rootlets. However, it is difficult to remove tumors that are of moderate or large size or located distally without sacrificing the affected nerve roots. In the present report, while we could spare normal rootlets in case 1, we could not preserve the affected nerve roots in case 2 because the tumor was large.

The AKA supplies most of the blood to the anterior spinal artery perfusing the anterior two-thirds of the spinal cord. In anatomical studies the AKA was found to originate from the left side in $68 \%$ to $72 \%$ and between the level of T8 and L1 in $68 \%$ to $91 \%$ of patients [17]. At spinal surgery, this artery must be preserved. In case 1 , we detected the AKA on preoperative 3D-CTA images and preserved it and its branches. We suggest that the preoperative identification of the AKA by $3 \mathrm{D}$-CTA angiography is useful for spinal surgery at the thoracolumbar junction.

Schwannomas usually show a hypointense or isointense signal on T1- and a hyperintense signal on T2-weighted images; they are homogeneously enhanced at MRI [2]. Important differential diagnoses are meningioma and tuberculous granuloma [2]. A histological characteristic of schwannoma is microhemorrhage [18]. According to Thamburaj et al. [18], the intratumoral presence of microhemorrhages on preoperative T2-weighted gradient echo MRI sequences helps to differentiate between schwannomas and other neoplastic tumors. Although we did not acquire T2-weighted gradient echo MRI scans, we suggest that this imaging modality should be used routinely in patients scheduled for surgery to address spinal tumors.

In conclusion, we reported two patients with ventral schwannoma of the thoracolumar spine and presented a review of the literature. The tumors were successfully 
removed using the posterior approach. We recommend the preoperative deliberation of imaging studies to obtain a differential diagnosis, to choose the optimal surgical approach, and to render spinal surgery as safe as possible.

\section{Conflict of Interest}

No potential conflict of interest relevant to this article was reported.

\section{Acknowledgments}

We are grateful to Dr. Hajime Yonezawa for data collection, Dr. Takafumi Mitsuhara and Professor Dr. Kaoru Kurisu for clinical assistance, and Ursula Petralia (Washington, USA) and Bohara Manoj for editorial assistance in the preparation of this manuscript.

\section{References}

1. Ueda R, Yoshida K, Kawase T. Intradural C-1 ventral root schwannomas treated by surgical resection via the lateral suboccipital transcondylar approach: three case reports. Neurol Med Chir (Tokyo) 2006;46:298301.

2. Mahore A, Chagla A, Goel A. Giant ventral midline schwannoma of cervical spine: agonies and nuances. J Korean Neurosurg Soc 2010;47:454-7.

3. Kanemoto Y, Ohnishi H, Koshimae N, et al. Ventral T-1 neurinoma removed via hemilaminectomy without costotransversectomy: case report. Neurol Med Chir (Tokyo) 1999;39:685-8.

4. Hori T, Takakura K, Sano K. Spinal neurinomas: clinical analysis of 45 surgical cases. Neurol Med Chir (Tokyo) 1984;24:471-7.

5. Angevine PD, Kellner C, Haque RM, McCormick PC. Surgical management of ventral intradural spinal lesions. J Neurosurg Spine 2011;15:28-37.

6. O'Toole JE, McCormick PC. Midline ventral intradural schwannoma of the cervical spinal cord resected via anterior corpectomy with reconstruction: technical case report and review of the literature. Neurosurgery 2003;52:1482-5.
7. Yasuda M, Bresson D, Cornelius JF, George B. Anterolateral approach without fixation for resection of an intradural schwannoma of the cervical spinal canal: technical note. Neurosurgery 2009;65:1178-81.

8. Ashour A, Rautenberg M, Buhl R, Mehdorn HM. Giant ventral intradural extramedullary neuroma: case report. Neurosurgery 1999;44:1338-40.

9. Chen SL, Zhang GL, Zhang HW, Lei T, Hu CC. Arachnoid adhesion caused by SURGICEL after operation for ventral spinal schwannoma. Chin Med J (Engl) 2010;123:3167-8.

10. Crockard HA, Sen CN. The transoral approach for the management of intradural lesions at the craniovertebral junction: review of 7 cases. Neurosurgery 1991;28:88-97.

11. Steck JC, Dietze DD, Fessler RG. Posterolateral approach to intradural extramedullary thoracic tumors. J Neurosurg 1994;81:202-5.

12. Singer RJ, Clough J, Johnson M, Atkinson JB, Copeland M. Pigmented schwannoma of the ventral spinal cord. South Med J 1999;92:532-4.

13. Parlato C, Tessitore E, Schonauer C, Moraci A. Management of benign craniovertebral junction tumors. Acta Neurochir (Wien) 2003;145:31-6.

14. Casha S, Xie JC, Hurlbert RJ. Anterior corpectomy approach for removal of a cervical intradural schwannoma. Can J Neurol Sci 2008;35:106-10.

15. Mahore A, Muzumdar D, Chagla A, Goel A. Pure ventral midline long segment schwannoma of the cervicodorsal spine: a case report. Turk Neurosurg 2009;19:302-5.

16. Arslan M, Comert A, Acar HI, et al. Lumbosacral intrathecal nerve roots: an anatomical study. Acta Neurochir (Wien) 2011;153:1435-42.

17. Muraki S, Tanaka A, Miyajima M, Harada R, Watanabe N, Hyodoh H. Adamkiewicz artery demonstrated by MRA for operated posterior mediastinal tumors. Ann Thorac Cardiovasc Surg 2006;12:270-2.

18. Thamburaj K, Radhakrishnan VV, Thomas B, Nair S, Menon G. Intratumoral microhemorrhages on $\mathrm{T}^{*}$ weighted gradient-echo imaging helps differentiate vestibular schwannoma from meningioma. AJNR Am J Neuroradiol 2008;29:552-7. 